\title{
Comparar las comparaciones jurídicas: observaciones al margen de la Introducción al derecho comparado de Alessandro Somma*
}

\section{Pablo Moreno Cruz}

Sumario. i. Comparación jurídica y antiformalismo interpretativo. II. La función del derecho comparado y sus peligros latentes. III. La cartografía global: entre descripción y construcción de sistemas y tradiciones. Iv. La mutación jurídica. v. ¿Cómo comparar? vi. Sommas y restas.

\section{Comparación jurídica y antiformalismo interpretativo}

El antiformalismo interpretativo nunca fue patrimonio exclusivo de la comparación jurídica: basta remontarse a los últimos años del siglo xIx y a las primera décadas del siglo xx para encontrarse con varios de los exponentes más representativos de la llamada 'rebelión contra el formalismo': conjunto de movimientos de matrices filosóficas diferentes que, en su conjunto, se consolidaron como formas variadas de resistencia al positivismo legislativo, es decir, a la versión más ingenua del positivismo jurídico. Además, el antiformalismo interpretativo

Fecha de recepción: I9 de abril de 20I7. Fecha de aceptación: 22 de mayo de 2017. Para citar el artículo: Moreno Cruz, P., "Comparar las comparaciones jurídicas: observaciones al margen de la Introducción al derecho comparado de Alessandro Somma", Revista de Derecho Privado, Universidad Externado de Colombia, n. ${ }^{\circ}$ 32, enero-junio de 2017, 49I-5I2. DOI: https://doi.org/ro. I860 I/o I234366.n32.I 7 / Soмma, A., Introduzione al diritto comparato, Roma-Bari, Laterza, 20 I4, trad. esp. Conde Naranjo, Introducción al derecho comparado, Madrid, Universidad Carlos iII de Madrid, 2015. Las citas textuales fueron tomadas de la versión en español del libro, disponible en: http://e-archivo.uc3m.es/bitstream/id/92578/introduccion_ somma_hd 34_2015.pdf

** Doctorado en Comparación Jurídica e Histórico-jurídica. Docente investigador de la Universidad Externado de Colombia, Bogotá, Colombia. Docente de Diritto delle Americhe de la Università degli Studi di Ferrara, Ferrara, Italia. pabloa.moreno@uexternado.edu.co 
tampoco es, actualmente, patrimonio exclusivo de la comparación jurídica: en la actualidad, muchas teorías normativas de la interpretación se construyen izando esta bandera, a veces con acepciones de ‘antiformalismo' casi del todo contrastantes.

Si es así, ¿por qué se justificaría inaugurar un libro sobre la comparación jurídica reiterando, nuevamente, el fuerte contraste entre el derecho comparado y el positivismo jurídico ideológico? Para Alessandro Somma ${ }^{\mathrm{I}}$ las respuestas son varias, y muchas de ellas las formula en la primera parte de su libro Introduzione al diritto comparato (Roma-Bari, Laterza, 2014; trad. Conde Naranjo, Introducción al derecho comparado, Madrid, Universidad Carlos III de Madrid, 20 I 5).

En efecto, Somma considera, ya desde el preámbulo, que, lejos de haberse superado el legicentrismo y el dogmatismo que caracterizó el ejercicio y el análisis del derecho desde el siglo xIx, "[e]l legicentrismo se manifiesta hoy como servilismo exegético respecto a las palabras de las fuentes de producción del derecho internacional y supranacional, mientras que el actual dogmatismo es producido por la ciencia económica, más que el elaborado autónomamente por la ciencia jurídica” (p. I3).

Es precisamente bajo este presupuesto que el autor insiste en enfatizar la función "crítica" y "subversiva" del derecho comparado. Una función que, en primer término, resultaría justificada como contraposición a dos hechos concretos: i) la tradicional representación de las fuentes del derecho que identifica (desde un punto de vista descriptivo) e impone (desde un punto de vista prescriptivo) una prioridad hegemónica de las fuentes formales; y, ii) la estrategia de los juristas que parecen operar como guardianes de un poder que se consolida mediante la negación de la relación entre derecho y política.

Bajo estas premisas, Somma emplea una distinción (ya famosa, pero con otros significados, en la obra de H. L. A. Hart) entre puntos de vista del análisis y el uso del derecho. A un punto de vista interno se opondría un punto de vista externo caracterizado por una extensión de "la noción de fuente del derecho a los diversos operadores llamados de algún modo a medirse con las palabras del legislador: para valorar las fuentes sustanciales del derecho, más allá de las formales". Más aún. Se extendería a todas las reglas sociales, y sus respectivas sanciones, "que se revelen capaces de dirigir el comportamiento [...] Deben considerarse también las normas de comportamiento no referibles al legislador, como las normas maduradas en el ámbito de un grupo profesional, en el seno de una comunidad en la que se comparten orientaciones políticas o religiosas, o simplemente a un círculo de amigos" (p. 28).

Una perspectiva de este tipo abre el estudio del fenómeno jurídico a una dimensión sociológica que valoriza el análisis de la eficacia de las normas (sobre todo, pero no solo) jurídicas y su capacidad para condicionar las conductas. Un

I Profesor ordinario de Derecho Comparado, Università degli Studi di Ferrara, Italia. 
análisis que debe tener en consideración que todo actor jurídico (juez, abogado, funcionario público, etc.) es un actor político que pretende, mediante el acto interpretativo, adscribir el significado más conveniente a sus intereses, abandonando, muchas veces, el significado literal de los enunciados del legislador. En estos términos, para Somma, la interpretación es, entonces, una práctica política dirigida a concretar una específica "distribución imperativa de valores y bienes, es decir, una modalidad para concretar compromisos en torno a varias opciones sobre el modo de coordinar intereses contrastantes" (p. 32 ).

En este contexto, asumir la existencia de una pluralidad de centros de interés cobra relevancia fundamental si se quiere capturar el contenido de los usos políticos en el acto de interpretación del derecho. Cualquier institución se configura como centro de interés; centros de interés que (desde una perspectiva institucionalista) operan, también, muchos de ellos, como centros inestables, por fuera, o también al interior, de las instituciones más estables, al tiempo que condicionan la adscripción de significados a la palabra de la ley.

La pluralidad de centros de interés (también muchos de ellos hostiles al ordenamiento jurídico estatal) refleja, entonces, una pluralidad de detentadores, más o menos consolidados, del poder de producción de normas o, para decirlo brevemente, refleja, al menos desde un punto de vista empírico, un pluralismo jurídico. Un fenómeno que, redimensionando el alcance del monopolio del poder soberano en el acto de producción del derecho, justifica, precisamente, el análisis del fenómeno jurídico a partir, también, del análisis sobre la eficacia de las normas sociales: es posible ocultar el fenómeno del pluralismo o, incluso, declarar la invalidez de las normas que se producen debido a condicionamientos políticos fuera del ordenamiento jurídico estatal; pero, en ambos casos, no se puede "impedir que sean eficaces, es decir, que sean seguidos por aquellos a quienes van dirigidos, tal vez por los condicionamientos ejercidos por el sistema sancionatorio ideado para castigar sus vulneraciones" (p. 37).

Ese eventual acto de ocultamiento del fenómeno del pluralismo jurídico en defensa del principio de monopolio del soberano en la producción del derecho -que se suma a otras mitificaciones tales como la idea de interpretaciones "correctas" de los enunciados normativos, la idea de ordenamientos jurídicos coherentes y completos, entre otras- encuentra su germen, también, en la narración que de la propia tradición hacen y repiten los juristas al momento de la construcción de la memoria del propio pasado. Así, sea que se hable de tradición jurídica o de experiencia jurídica, para Somma esa reconstrucción narrativa del pasado jurídico es, en sí misma, algo sospechosa -por su parcialidad, por las posibles construcciones de falsas continuidades y falsas rupturas, por tratarse, a fin de cuentas, de reconstrucciones que gobiernan una específica distribución de valores; pero también útil, tanto para rescatar la complejidad del conjunto de preceptos que gobiernan los comportamientos humanos como para desechar el uso aún más sospechoso de (una específica forma de entender) la locución 'ordenamiento jurídico'. 


\section{La función del derecho comparado y sus peligros latentes}

En pocas palabras, Somma, en la primera parte de su libro, fundamentalmente se dedica a indicar el qué (en realidad, alguna parte del qué2) de la comparación jurídica: la pluralidad de las fuentes del derecho (no solo formales, no solo jurídicas); la carga política que sustenta el acto de interpretación condicionada por la pluralidad de centros de interés y, en fin, las reconstrucciones del pasado, de la memoria social, en manos de los juristas y sus estrategias para la legitimación de su saber (aparentemente solo) técnico.

En cambio, en la segunda parte del libro, el autor se concentra en los objetivos de la comparación jurídica, en el porqué de la comparación jurídica. Una pregunta que, en realidad, Somma asume con desconfianza debido a la tendencia creciente a enumerar objetivos que condicionan el acto de comparación a la aprobación del grupo de interés que debería servirse de tal objetivo. En efecto, Somma -después de recurrir a la conocida afirmación de Rodolfo Sacco, quien, reivindicando la legitimación científica de la comparación jurídica, recuerda que nadie le pregunta a un astrónomo cuáles son los objetivos de su saber- enfatiza que los comparatistas se dedican, en cambio, a recordar "con demasiada frecuencia que su saber alimenta 'varias formas de progreso y profilaxis social': de la paz mundial a la construcción de un derecho internacional, supranacional o transnacional, pasando por la mejora del derecho nacional" (p. 57) ${ }^{3}$.

Dentro de esa serie de objetivos, la distinción que emplea Somma entre comparación que une y comparación que divide resulta muy útil, no solo por su vocación explicativa. En efecto, como bien precisa el autor, la tendencia de los comparatistas, ya desde los albores de la comparación jurídica4, es auto-identi-

2 Tal vez porque no considerarlo pertinente, Somma no incluye en esta parte del libro varios qué, varios objetos de la comparación, que sin duda son prioritarios. En efecto, más adelante se ocupa de (i) el estudio y la clasificación de los sistemas jurídicos desde una perspectiva macrocomparada (ver infra III) y, después, de (ii) la mutación jurídica y, entones, de la circulación de modelos jurídicos (ver infra Iv). Ambos, sin duda, objetos de la comparación jurídica. De hecho, creo, los aspectos que dan una autonomía epistemológica al derecho comparado frente a otros enfoques descriptivos del derecho menos amplios y menos dinámicos.

3 Esta afirmación de Somma habría podido ser algo más radical: habría podido afirmar, creo que con razón, que, en estricto sentido, cuando el derecho comparado asume una perspectiva teórica, necesariamente debe cumplir, solo y exclusivamente, una función descriptiva (de su objeto de estudio: el derecho) con una pretensión, para decirlo en términos weberianos, no-valorativa. Sin embargo, al parecer, para Somma esto resultaría equivocado en cuanto demasiado radical: en efecto, afirma el autor, "[n]o se pretende alimentar aquí la creencia en que las ciencias solo pueden ser consideradas como tales en la medida en que proporcionan conocimientos liberados o distinguibles de la ideología, entre otras razones porque se trata de la creencia fundacional del dogma iuspositivista" (p. 57).

4 Sin negar varios antecedentes, algunos comparatistas, entre ellos Somma, eligen, como momento de inauguración, o momento de auto-comprensión, el Congreso en Paris sobre Legislación Comparada del año igoo. Son antecedentes las diferentes asociaciones de derecho comparado (y sus respectivos productos): la Sociedad de Legislación Comparada, con sede en Paris (г 896); 
ficar el derecho comparado como ciencia y auto-presentarlo al servicio de una teoría del progreso: "partiendo de una filosofía de la historia de matriz evolucionista" (p. 57) el comparatista podría identificar los rasgos comunes entre los ordenamientos jurídicos para garantizar una posible unificación.

Esta tendencia seguramente no se ha desvanecido: como se precisará en seguida, la pretensión unificadora, que también se manifestó, con amplias tendencias iusnaturalistas, en la segunda posguerra, hoy impera, con nuevas caras y con argumentos (engañosos, a pesar de ser) más sofisticados. En efecto, Somma emplea el ejemplo clásico de la unificación del derecho privado de la Unión Europea, que, en su sentir, es la prueba de "cómo, al momento en que la legitimación de un campo del saber se hace depender de la individualización de finalidades específicas, inevitablemente acaba condicionando su agenda cultural y devaluando su potencial aportación crítica" (p. 66).

En términos más precisos, la producción normativa de las diferentes instituciones europeas en alguna medida relativa al derecho privado generó, en un principio, dos reacciones específicas: de un lado, una especie de renacer de "un estilo muy cercano al estilo de la Escuela de la exégesis" que se manifestaba en comentarios de directivas y reglamentos; de otro lado, un esfuerzo por reconstruir improbables sistemáticas capaces de "reconducir a la unidad las palabras del legislador europeo, para denunciar después las carencias y las peligrosas desviaciones respecto a una tradición que tampoco aparece mejor definida” (p. 67).

Ante este panorama, la ciencia jurídica ${ }^{5}$ y la jurisprudencia local se convirtieron en las fuentes que respondieron a esta tendencia tratando de producir un derecho europeo, no ya desde arriba, sino desde abajo.

En cuanto a la ciencia jurídica europea y su esfuerzo por consolidar la unidad del derecho privado europeo, Somma precisa ${ }^{6}$ que la comparación jurídica (al menos aquella comparación jurídica que adscribió a la pretensión de unificación) resultó indiscutiblemente condicionada, ya desde el Cuadro Común de Referencia, por el deber de exaltar "la libertad contractual, devaluando, por tanto, los correctivos desarrollados a nivel nacional en aplicación del principio de paridad sustancial". Un condicionamiento que, además, derivaría del siguiente hecho: "se consideró también prioritario el enlace entre los estudiosos y los titulares de intereses económicos y profesionales, constituidos en su correspondiente comi-

la Asociación Internacional para la Ciencia Jurídica y la Economía Política Comparadas, con sede en Berlín (I 894), y la Sociedad de Derecho Comparado, con sede en Londres (I896).

5 Piénsese en los Principios de Derecho de los Contratos patrocinados por Ole Lando y, más adelante, con sustanciales diferencias, también metodológicas, en el Cuadro Común de Referencia del derecho contractual europeo y en el posterior Estudio de Viabilidad para un Futuro Instrumento de Derecho Contractual Europeo.

6 Somma se había ocupado del tema en otros escritos. Ver, ej., Soмma, A., Introducción crítica al derecho europeo de los contratos, trad. de Moreno Cruz, P. y Rodríguez Olmos, J., Madrid, Marcial Pons, 2008. 
sión, cuyas indicaciones quisieron considerarse, en cierto modo, vinculantes para la red de estudiosos" (p. 69). De este modo, “el comparatista acaba endosándose los hábitos de una doctrina resuelta a alimentar el positivismo legislativo o, al menos, una versión revisada de este": la doctrina comparatista termina degradada a mera traductora de términos técnicos y "las decisiones políticas a las que presta abrigo son las adoptadas por el mercado, más que por el circuito democrático" (p. 7o).

En cuanto a la jurisprudencia, el análisis es algo diferente. Somma precisa que la construcción desde debajo de un derecho privado europeo se manifiesta a nivel de la fuente jurisprudencial mediante el uso por parte de los jueces nacionales de las decisiones (obviamente no vinculantes) proferidas por otros jueces nacionales de otros países de la Unión. Una práctica referida, entonces, al uso explícito y/o implícito del derecho foráneo; una práctica, por cierto, en evidente contradicción con el (casi inmediatamente menguado) ideal del positivismo legislativo de centralizar la producción del derecho en el Estado-nación a la luz, también, salvo en el caso suizo, de las primeras codificaciones civiles de la europea continental, posteriormente interpretadas en sentido contrario.

En este evento -obviamente entendiendo como actividad comparativa el uso por parte del juez local del derecho extranjero- el derecho comparado opera, de forma explícita y (en realidad, dice Somma, la mayoría de las veces de forma) implícita en dos sentidos posibles.

De un lado, como patrocinador de la unificación del derecho privado europeo. Unificación que también se manifiesta cuando el uso del derecho foráneo (europeo) está dirigido a legitimar cambios internos que encuentran resistencias por parte de otras fuentes: "también en estos casos se acaba usando la comparación en clave unificadora, al menos en el ámbito de ordenamientos pertenecientes a la misma tradición que es inducida, por tanto, a cambiar de acuerdo con líneas culturales compartidas" (p. 72 ).

De otro lado, como acto de resistencia a la pretensión unificadora, el uso del derecho foráneo operaría como instrumento de rechazo de "la evolución de un derecho nacional en sentido unificador, para promover la distinción de otros derechos y justificar así la persistencia de su alteridad”.

En este último caso, se habla de un derecho comparado que divide, una “comparación identitaria”. Así, y en términos más generales, un uso del derecho comparado que, en cambio de concentrarse en la identificación de las similitudes con una perspectiva constructiva, valoriza el contexto para identificar aquellas diferencias que, de todas formas, "estaban naturalmente destinadas a emerger en el momento en el que la solución técnico-jurídica fuese anclada a las circunstancias concretas en las que había tomado cuerpo" (p. 75), es decir, la experiencia y tradición jurídica local.

Para Somma, este contraste en el uso del derecho comparado por parte de los jueces locales es la oportunidad para profundizar un aspecto de fundamen- 
tal importancia metodológica. A partir de la tensión entre enfoques modernos (unificadores) y posmodernos (identitarios) 7 , Somma afronta la evidente contradicción entre la adopción de una función del derecho comparado (en cualquier forma) comprometida y la pretensión descriptiva del derecho como actividad científica. En pocas palabras, Somma considera que favorecer cualquiera de estos objetivos -i.e.: unificar el derecho vs. tutelar identidades locales- implica (sin duda, creo yo) abandonar la pretensión descriptiva: "quien define la comparación como ciencia dirigida a poner de relieve analogías y diferencias no puede luego limitarse a confeccionar descripciones en las que favorezca apriorísticamente a las segundas en perjuicio de las primeras" (p. 77).

Claro, Somma, como ya se precisó, no asume una perspectiva que permita una descripción del objeto del derecho comparado (el qué del derecho comparado) a la luz de una posible equiparación entre ciencias sociales y ciencias naturales, es decir, no defiende una perspectiva cientificista y, de hecho, incluso, descarta la posibilidad de análisis neutrales que nieguen "un comprender afligido por parcialidades ineludibles" (p. 78). Su pretensión, más bien, a partir de una comprensión compleja, contaminada y dinámica de las tradiciones jurídicas, es descartar la idoneidad de adscribir una función específica al derecho comparado que termine por favorecer la negación de las diferencias o, en cambio, de las similitudes. Incluso, aunque Somma parece que valoriza un enfoque diferencial a favor de la tutela de las identidades, para él "la comparación jurídica puede entonces estudiar [las tradiciones], enfocando la diversidad indispensable para preservar su identidad, pero evitando reducirla a una inconmensurabilidad que niegue su interdependencia" (p. 79).

\section{La cartografía global: entre descripción y construcción de sistemas y tradiciones}

En el análisis comparado, las dificultades más relevantes derivan, precisamente, del acto de identificación de las diferencias y/o las similitudes, cuando las pretensiones del acto de comparación están dirigidas a capturar una especie de cartografía a nivel global. Las agrupaciones o, en cambio, las separaciones (radicales o tenues) entre las diferentes realidades normativas poseen una fuerza condicionante (performativa) en cuanto instrumento simplificado de re-presentación normativa del derecho global.

Pues bien, Somma dedica el segundo capítulo de la segunda parte de su libro -"Sistemas y familias de sistemas"- precisamente al análisis de los ejercicios cartográficos elaborados por la literatura comparada. Un análisis que, también a partir de las reconstrucciones de diferentes autores (ya desde el Congreso de

7 Sobre este punto el autor regresa, con mayor profundidad, en la última parte de su libro referida a las metodologías de la comparación jurídica. Ver infra v. 
Paris del año i90o) busca mostrar el carácter geopolítico de tales ejercicios de mapeo: la sistemática comparada como "geografía de los cuerpos políticos" .

En efecto, ya la primera parte de la reconstrucción sugerida por Somma que comienza con Adhémar Esmein9, pasa por Henri Lévy-Ulmann ${ }^{\text {Io, }}$, Michele Sarfatti ${ }^{\mathrm{II}}$ y Enrique Martínez $\mathrm{Paz}^{\mathrm{I} 2}$, y cierra con la propuesta de René David ${ }^{\mathrm{I}}$, que contrastó aquella de Pierre Arminjom, Boris Nolde y Martin Wolff ${ }^{\mathrm{I}}$ y que, a su vez, fue contestada por aquella de Zweigert y Kötz ${ }^{15}$ - sirve para corroborar al menos tres aspectos: i) divergencias específicas en relación con una división global entre centro (Europa) y periferia, privilegiando las más de las veces una perspectiva eurocéntrica; ii) un condicionamiento evidente en atención a los centros globales de poder económico y/o bélico y/o político; $y$, iii) una tendencia ambivalente a distinguir o, en cambio, acomunar el derecho de matriz alemana y el derecho de matriz francesa.

Solo en relación con el tercer punto, Somma recuerda cómo Zweigert y Kötz, a principios de los años setenta del siglo xx, formularon una propuesta que, siguiendo la tendencia de la clasificación propuesta por Arminjon, Nolde y Wolff, y, por tanto, en contravía de la entonces hegemónica propuesta de David, reivindica, a partir del concepto de estilo del sistema -i.e.: la evolución histórica; la mentalidad jurídica; las ideologías; las instituciones jurídicas; los tipos de fuentes del derecho; los métodos de interpretación (pp. 85-87)-, una distinción entre el derecho germánico y el derecho francés en la Europa continental. Una distinción que, en esa época, como precisa Somma, se había diluido como consecuencia de la contraposición entre el bloque socialista y el Occidente, y también como consecuencia de la pretensión "de presentar a este último como caracterizado por la distinción entre países de common law y países de familia romano-germánica" (p. 84). Una distinción omitida (aquella entre derecho francés y derecho alemán) que, incluso para quienes siguieron, al menos en parte, la estructura de René David, fue destinataria de re-elaboraciones a partir de

8 Sobre el punto ver, también, Monateri, P. G. La geopolitica del diritto. Genesi, governo e dissoluzione dei corpi politici, Roma-Bari, Laterza, 2013.

9 Esmein, A., "Le droit comparé et l'enseignement du droit", Bulletin de la Société de législation comparée, 1900, 379.

io Lévy-Ulmann, H., Observations générales sur les communications relatives au droit privé dans les pays étrangers, en Les transformations du droit dans les principaux pays depuis cinquante ans (I869-1919), t. I, Paris, Librairie du Conseil d'État et de la Société de législation comparée, I922, 85 ss.

i I SARfatti, M., Introduzione allo studio del diritto comparato, Torino, Giappichelli, 1933.

i2 Martínez Paz, E., Introducción al estudio del derecho civil comparado, Córdoba, Imprenta de la Universidad, I934.

I 3 David, R., Les grands systèmes de droit contemporains, Paris, Dalloz, I964.

I4 Arminjon, P.; Nolde, B. y Wolff, M., Traité de droit comparé, vol. i, Paris, LgdJ, I950.

I5 Zweigert, K. y Kötz, H., Einfuibrung in die Rechtsvergleichung, 3. ${ }^{a}$ ed., Tübingen, J.C.B. Mohr, 1996. 
una crítica a la supuesta unidad entre los diferentes sistemas pertenecientes a la familia romano-germánica: piénsese, por ejemplo, en la clasificación formulada por Gambaro y Sacco ${ }^{16}$.

Más allá de esta tensión específica relativa al mundo europeo (con sus efectivas repercusiones a nivel occidental), lo cierto es que, como precisa Somma, la mayoría de las clasificaciones elaboradas a la luz de la agrupación entre familias de sistemas jurídicos, que por cierto difícilmente escapan al elemento de la estatalidad, adolecen de etnocentrismo: expresan "a menudo tensiones etnocéntricas" que reflejarían, sobre todo, "lo que parece una natural inclinación occidental a la clasificación del otro, funcional a la composición de jerarquizaciones dirigidas a demostrar su inferioridad" (p. 89).

Somma dedica entonces algunas reflexiones a algunas (no todas las) perspectivas que, en cambio, han buscado escapar a los problemas de la estatalidad y del enfoque etnocéntrico. Recuerda, así, el trabajo de Léontine-Jean Constantines$\mathrm{Co}^{17}$-quien, en el sentir de Somma, supera el problema de la estatalidad, pero "no supera, en cambio, la visión jerárquica" (p. 91) - y su esfuerzo por reformular las clasificaciones tomando en consideración las sociedades modernas, las tradicionales y las primitivas, en atención a cuestiones tales como el estilo de vida, el contexto ético-teológico y el ambiente material. Recuerda también el trabajo de Jacques Vanderlinden ${ }^{18}$, quien supera el problema de la estatalidad, al tiempo que valoriza el pluralismo jurídico, cuando formula una clasificación que se enfoca en la fuente del derecho dominante (pero no de forma exclusiva, sino solo de forma preponderante) en el respectivo sistema: consuetudinario, doctrinal, jurisprudencial, legislativo y revelativo. Un énfasis importante es dado por Somma a la propuesta de Patrick Glenn ${ }^{19}$ quien, para el autor, por medio de su concepto de tradición, logró superar, en su esfuerzo cartográfico, los problemas de estatalidad, el etnocentrismo y la jerarquización, al tiempo que valorizó y puso en el centro de su reflexión el pluralismo jurídico. Glenn identifica siete tradiciones jurídicas, no inmutables, no puras, no autónomas: ctónica, talmúdica, civil law, islámica, common law, hindú y confuciana, donde la contraposición (sobre todo) entre tradición ctónica y tradición occidental, como derecho de la modernidad capitalista, reviste, para Somma, particular relevancia.

Con menos entusiasmo, Somma dedica su análisis a una propuesta que pretende valorar el pluralismo jurídico y la elaboración no-etnocéntrica de las clasificaciones globales, pero que, en su sentir, es insuficiente. En efecto, el autor, desde una perspectiva crítica, hace referencia a una temprana clasificación de

i6 Gambaro, A. y Sacco, R., Sistemi giuridici comparati, Torino, Utet, 2008.

i 7 Constantinesco, L-J., La scienza dei diritti comparati, Torino, Giappichelli, 2003.

i 8 Vanderlinden, J., Comparer les droits, Story-Scientia, Diegem, I 995.

I9 Glenn, P., Tradizioni giuridiche nel mondo, Bologna, Il Mulino, 20 I I. 
Ugo Mattei y Pier Giuseppe Monateri ${ }^{20}$ (en parte por ellos mismos ya superada), una cartografía que se construye a partir de la identificación del mecanismo de control social hegemónico en el respectivo sistema: familias de hegemonía profesional (el derecho), familias de hegemonía política y familias de hegemonía de la tradición.

Esta última clasificación sirve a Somma como instrumento de análisis crítico de los discursos constructores de la tradición jurídica occidental, prestando particular atención a la consolidación de la disociación entre derecho y política y aquella entre derecho y tradición. En concreto, Somma reconstruye los hechos (ya bien conocidos para los estudiosos del derecho comparado) que habrían determinado, en primera instancia, la distinción jerarquizada entre el Occidente y el resto del globo y, en segunda instancia, la justificación de la distinción igualmente jerarquizada entre el common law y el civil law.

En relación con la consolidación institucional del derecho y, entonces, la disociación entre derecho y religión, la referencia de Somma es, obviamente, a Harold Berman ${ }^{2 \mathrm{I}}$ y su reconstrucción de la revolución papal con la reforma gregoriana y la consolidación de la enseñanza universitaria en la Universidad de Bologna. Una revolución que habría determinado una serie de particularidades propias y exclusivas de la tradición jurídica occidental: (entre otras) la distinción institucional del derecho frente a los demás sistemas normativos; la entrega de la administración del derecho a un grupo profesional; la generación de "una ciencia llamada a sistematizar las reglas producidas por las instituciones jurídicas" (p. Io4). En cambio, en relación con la separación entre derecho y política, donde se enfatiza el discurso que termina por patrocinar la supremacía del common law, el énfasis se hace en la capacidad temprana que habría tenido esta familia de sistemas de consolidar una "juridicización del criterio político", ya desde los tiempos turbulentos de Edward Coke (siglo xviI) y, en Estados Unidos, con el juez Marshall y la famosa sentencia Marbury vs. Madison (г 803).

En términos generales, con base en el análisis del divorcio entre derecho y religión, y de aquel entre derecho y política, se dibujaría una especie de supremacía de la tradición jurídica occidental, así como, en su interior, una superioridad del common law frente al civil law.

Somma analiza este último fenómeno, que se ubica en el contexto de un contraste, característico de la literatura comparada, en relación con la tensión entre la identificación de una tendencia a la disolución de las distinciones entre ambas familias de sistemas -fundamentalmente construida con base en el análisis histórico y contemporáneo del contrastante alcance normativo de la jurispru-

20 Mattei, U. y Monateri, P. G., Introduzione breve al diritto comparato, Cedam, Padova, i 997 . Ver también Mattei, U., "Three Patterns of Law", The American Fournal of Comparative Law, 45, I997, 5 ss.

2 I Berman, H. J., Diritto e rivoluzione, Bologna, Il Mulino, I 998. 
dencia y de la legislación-, frente a una tendencia que, no obstante la cercanía empíricamente constatable, sigue identificando una distancia radical entre ambas familias, sea desde la perspectiva de las fuentes del derecho o desde sus instituciones, sea, sobre todo, en atención al estilo de los sistemas en sus aspectos incluso más profundos.

Muchas de las distinciones entre common law y civil law poseen una fuerza explicativa y descriptiva contundente; otras, a pesar de carecer de tal contundencia (p. ej., por excesiva simplificación), han sido empleadas, en cambio, en el proceso de jerarquización entre common law y civil law -jerarquización que se enfatiza cuando se toma en consideración la adscripción de significado a los valores que se consideran como fundamento del Occidente: cristianismo, democracia liberal y economía capitalista.

En relación con la construcción de la jerarquía entre common law y civil law, uno de los ejemplos afrontados por Somma (en realidad, un argumento que regresa constantemente a lo largo de su libro) se conecta con el discurso de la Nueva Economía Comparada que se consolida a partir de una enfatización de las premisas de la Nueva Economía Institucional y su conclusión según la cual "las reglas de juego, en la medida en que indican los requisitos para que un acuerdo sea considerado válido y, por tanto, asistido por el derecho, producen costes directamente proporcionales al nivel de injerencia de los poderes públicos en la actividad privada. De ahí se deriva que la intervención estatal está condenada a provocar un derrumbe del mercado, cuya eficiencia se ve en cambio favorecida por la diligente limitación de dicha intervención” (p. I I 2).

Como precisa Somma, la particularidad de este enfoque radica en que, si bien el objetivo de consolidar el bien común había sido conectado con la exaltación de las libertades económicas desde la contraposición, favorable al primero, entre "capitalismo neoamericano o de las economías de mercado liberales" y "capitalismo renano o economías de mercado coordinadas" (pp. Iо6- Ior), solo a partir de la perspectiva de la Nueva Economía Comparada se crea un nexo entre "las cualidades de un orden económico y el derecho en el que este se funda" (p. I I3). De hecho, mientras, en un principio, la superioridad del capitalismo neoamericano propio del common law contrastaba con la superioridad técnicojurídica adscrita al civil law, actualmente "la calidad de un modelo de capitalismo depende de que se rija según reglas del juego de matriz angloamericana y no europeo-continental" (p. I I 3 ).

Precisamente este pasaje resulta evidente en el estudio promovido por el Banco Mundial, el conocido Doing Business ${ }^{22}$, elaborado anualmente desde el año 2004, que, en palabras de Somma, concluye que "la tradición de comon law, en la medida en que instituye un 'gobierno limitado', debe ser preferida frente a la

22 Sobre este argumento Somma regresa varias veces en su libro. En especial, cuando se ocupa de la mutación jurídica (pp. I40-I44). Ver infra IV. 
tradición de civil law, con su 'inclinación a la intervención pública en la vida económica" (p. I I 3). La explicación de esta aparente incapacidad del civil law para afrontar de manera eficiente los retos del crecimiento económico fue formulada por la Nueva Economía Comparada (también) a partir de la llamada "teoría del origen legal": un estudio con evidentes "simplificaciones y forzamientos ideológicos" (p. I I4) que, a partir de una perspectiva histórica formalista y cientificista, califica al common law como el mejor derecho (pp. I I4- I I 7).

Para Somma, esta reconstrucción de la tradición jurídica occidental, en la forma hasta ahora analizada, no hace otra cosa que enfatizar la perspectiva etnocéntrica, situando en el vértice al derecho de matriz angloamericana y consolidando, por cierto, un escenario periférico heredero (y presentado como heredero) de tal tradición.

Un ejemplo que interesa particularmente a Somma es el relativo al derecho latinoamericano; un derecho que ha sido considerado y presentado por la literatura comparada exclusivamente como heredero, desde un punto de vista de los comparatistas con perspectiva privatista, del derecho del civil law (sobre todo, pero no solo, de la codificación francesa): herencia (adquirida por "['malos'] imitadores del modelo arbitrariamente elegido como parámetro y medida de centralidad", p. I2 I) que, bajo la perspectiva de la Nueva Economía Comparada, habría transmitido las patologías propias del civil law. Una herencia que, en cambio, desde el punto de vista de los comparatistas publicistas, sería también deudora, de todas formas, del derecho estadounidense (piénsese, p. ej., en el federalismo y en el presidencialismo).

En ambos casos, sin embargo, Latinoamérica se situaría en la periferia del centro de producción jurídica occidental. Esta es una perspectiva que se ha querido superar (para Somma, sin éxito) mediante un enfoque clasificatorio que, como ya fue mencionado, toma en consideración, no las realidades estatales, sino la hegemonía de los mecanismos de control social -derecho, política y religión. Un enfoque que, sin embargo, al incluir a los sistemas latinoamericanos en el grupo de los sistemas con hegemonía de la política -"motivada por la circunstancia de que todavía no han completado el recorrido hacia la realización del que se considera carácter fundante de los sistemas de hegemonía profesional” (p. I 22)-, en realidad conduce a la conclusión según la cual, aunque "el área latinoamericana no constituye la periferia de un modelo, representa sin embargo el centro de un modelo distinto considerado periférico en su conjunto, en la medida en que está atrasado respecto a cuanto identifica a las experiencias occidentales" (p. I23).

Pues bien, en cuanto a Latinoamérica, Somma prefiere una perspectiva de análisis algo diferente. En efecto, rescata (así como en su momento lo hizo, p. ej., Mario Losano ${ }^{23}$ ) el valor de la tradición indígena, pero sin caer en la tentación

23 Losano, M. G., I grandi sistemi giuridici. Introduzione ai diritti europei ed extraeuropei, Roma-Bari, Laterza, 2000. 
de adscribir a esta peculiaridad el valor negativo de ser la fuente de atraso en cuanto fuente de ruptura pre-moderna con la (noción más tradicional de) modernidad, vinculada a nociones específicas de democracia y capitalismo. Por el contrario, Somma considera que es posible "hablar de modernidades en plural y considerar el cruce entre el derecho indígena y el desarrollo de la democracia y del capitalismo como el rasgo que distingue a la modernidad latinoamericana de la occidental" (p. I 24).

Para este análisis, el autor se sirve, justa y nuevamente, de Glenn y su teoría sobre las tradiciones jurídicas. En especial, de la identificación, dentro de la tradición jurídica latinoamericana, de una tradición ctónica -junto con una clara influencia de la tradición del civil law que no necesariamente implica, al menos no siempre, una "sincera admiración”. Una descripción que, en palabras de Somma, permitiría "que la democracia recupere terreno respecto al capitalismo", al tiempo que permitiría "centrar en este equilibrio diferente la renovación de la modernidad occidental”. En pocas palabras, Somma considera, no solo en este libro ${ }^{24}$, que tal re-equilibrio, que no niega, sino que valoriza la relación entre modernidad y derecho indígena, permitiría, mediante una democratización del circuito de la economía, superar el individualismo occidental, sin que sea un "indicio de tensiones autoritarias". Es una relación que puede ser "presagio de maneras alternativas de entender la modernidad" (pp. I 24-I25).

\section{La mutación jurídica}

Un enfoque no etnocéntrico y no estático en el análisis de los sistemas jurídicos debe estar alimentado, también, por la necesaria aceptación de dos premisas: la continua circulación de información entre los diferentes sistemas y la imposibilidad de identificar un único, estable e impermeable centro de producción de información (sea, o no, hegemónico). Ambas premisas suponen, a su vez, que el objeto de estudio de la comparación jurídica se traslada, desde el análisis estático, hacia el análisis (no jerarquizado) de los flujos de información, es decir, un análisis dinámico. Una perspectiva que, como precisa Somma, puede ser rastreada en la perspectiva metodológica de la historia conocida como 'historia global', cuya aplicación al derecho por parte de Thomas Duve busca revitalizar el análisis histórico (sobre todo europeo) a partir de un análisis no eurocéntrico.

Obviamente, sería un error pensar que el derecho comparado se ha cristalizado únicamente en la clasificación estática de los sistemas ignorando la perspectiva dinámica y, entonces, el fenómeno de la mutación jurídica. Por el contrario,

24 Somma A., "Le parole della modernizzazione latinoamericana. Centro, periferia, individuo e ordine", en Polotto, M. R.; Keiser, T. y Duve, T. (eds.), América Latina y Europa en la primera mitad del siglo XX, Max Planck Institut für Europäische Rechtsgeschichte, Frankfurt a.M., 20 5 , I I-46. 
la mutación jurídica, desde siempre, ha sido objeto de análisis por parte de la literatura comparada (en general, "los comparatistas consideran que el análisis de la mutación jurídica forma parte y es incluso constitutivo de la investigación sistemológica”, p. I 29); pero la perspectiva no siempre comulga con un punto de vista no-etnocéntrico y, sobre todo, no jerarquizado.

A este fenómeno Somma dedica especial atención. En primer término, y con enfoque crítico, a la perspectiva evolucionista que, ya desde el Congreso de Paris, asume que los derechos mutan porque siguen (deberían seguir) un camino específico dirigido a consolidar un estado de cosas conforme a cuanto se considera sea el mejor derecho. Una perspectiva de análisis que, sin embargo, es claramente contestada por la perspectiva difusionista que estima que el derecho muta como resultado del contacto entre culturas. Fundamentalmente: la imitación como la fuente única de los cambios legales.

Sin embargo, Somma también formula algunas críticas al difusionismo ${ }^{25}$; críticas que podrían ser reconstruidas del siguiente modo: i) el concepto de prestigio (formulado por Rodolfo Sacco), entendido como única razón de la circulación de modelos jurídicos, ii) al tiempo que "oculta la recepción impuesta de modelos, dictada por las relaciones de poder, como las originadas por el colonialismo, que han sido el principal motor de circulación del derecho occidental” (p. I 32 ), iii) revive una perspectiva de matriz evolucionista, iv) consolida ciertos modelos como los más apetecidos, v) cuya recepción divide al mundo entre creadores, de un lado, y malos y pasivos imitadores, del otro.

Se trata de un razonamiento que, para Somma -además de que su confirmación carece de fuerza probatoria, en cuanto se fundamenta en estudios que muestran solo una "aparente" atención al dato empírico-, presta muy poca atención al poder político; esto, al menos, en la versión de Watson ${ }^{26}$; versión, esta última, formulada en la forma de una teoría de los trasplantes y que fue destinataria de relevantes críticas, sobre todo aquellas formuladas, entre otros, por Pierre Legrand ${ }^{27}$ con su insistencia en la imposibilidad de hablar de trasplantes, si ello significa una fiel recepción de la información jurídica objeto de circulación.

Más allá de la forma como Somma entiende y critica el difusionismo -y aunque creo que algunos matices y especificidades permitirían ver con otros ojos conceptos como aquel de prestigio ${ }^{28}$-, lo cierto es que el discurso sobre la

25 Somma, cuando se ocupa del estructuralismo en el acápite dedicado a las metodologías del derecho comparado, aborda otros puntos del difusionismo. Ver infra $\mathrm{v}$.

26 Watson, A., Legal Transplants. An Approach to Comparative Law, University of Georgia Press, Athens (Ga.), I993.

27 Ver, p. ej., Legrand, P., Le droit comparé, puf, Paris, I999; Id., "What 'legal transplant'?", en NeLKen, D. y Feest, J. (eds.), Adapting Legal Cultures, Hart Publishing, Oxford-Portland, 200 , 55 ss.

28 En cuanto al razonamiento mediante el cual construí la crítica de Somma al difusionismo, específicamente en relación con el concepto de prestigio, pareciera ser que para que dicho razonamiento sea admisible es necesario que se entienda 'prestigio', concomitantemente, en los 
mutación jurídica y la circulación de datos jurídicos requiere, actualmente, un enfoque más profundo en relación con la imposición de imitaciones: especialmente aquellas de matriz económica, en su tiempo menos relevantes para la primera literatura difusionista.

En efecto, Somma, no solo en este escrito ${ }^{29}$, se ha mostrado muy sensible a este fenómeno: específicamente al análisis de la circulación de una concepción específica de desarrollo económico difundida por las instituciones hijas de los Acuerdos de Bretton Woods: Banco Mundial y Fondo Monetario Internacional. Una concepción dirigida a la promoción de una concreta concepción de democracia, a su vez condicionada por una concreta concepción de capitalismo ideológicamente comprometido con una perspectiva neoliberal que disuelve (y, en realidad, tiende a apoderarse de) las competencias del poder político.

En este escenario, Somma se concentra en el movimiento de Law and Development que en sus dos fases históricas (p. I36) simplificó la complejidad del desarrollo tout court en la forma de desarrollo económico y abrió la puerta, a comienzos de este siglo, a la ya mencionada Nueva Economía Comparada que "no hace sino amplificar los esfuerzos de esa segunda fase del movimiento Law and development, combinándolos con un uso más explícito de prácticas dirigidas a imponer la circulación del modelo de common law y, al mismo tiempo, a contrarrestar a su tradicional competidor: el modelo de civil law, en especial a su versión francesa" (p. I 38 ). Se trata de una perspectiva construida bajo la creencia (por cierto, contraria a la experiencia: una "ingenua creencia”) según la cual "el derecho constituye un poderoso instrumento de ingeniería social, cuya eficacia depende de la cualidad de las reglas adoptadas o, mejor, impuestas, y no del contexto en el que son aplicadas" (p. г 38 ).

siguientes términos: (i) si $\mathrm{X}$ (comparatista) afirma que el sistema $\mathrm{S}$ considera que la información I es prestigiosa, es necesario que $\mathrm{X}$ considere, a su vez, que $\mathrm{S}$ es prestigioso; (ii) como una propiedad que es adscrita solo por el sistema receptor y (iii) como una propiedad que necesariamente es excluyente de otras razones de los flujos jurídicos. Pero si, en cambio, 'prestigio' fuese entendido de un modo diferente (un agregado de tres condiciones concomitantes): (i) como un juicio de valor sobre un dato normativo que implica solo que una clase de sujetos lo considera (cree que es) mejor, superior en términos comparativos frente a la realidad normativa del sistema receptor, y dicha creencia se convierte en la justificación de la imitación; (ii) como una creencia construida por el sistema receptor y/o el sistema productor de la información objeto del flujo; (iii) como una razón de los flujos jurídicos necesaria, pero no siempre suficiente: no puede haber flujo sin prestigio; pero no siempre es suficiente el prestigio para que se verifique la circulación. Bajo esta definición, las críticas formuladas por Somma contra el difusionismo, al menos en relación con el concepto de prestigio, pierden fuerza, a condición de que se acepte que en el proceso de recepción se verifica siempre una mutación de la información; condición que no depende del concepto de prestigio. Sobre esta definición de prestigio ver Moreno Cruz P. y Benavides J. L., "La contratación pública en América Latina y la comparación jurídica”, en La contratación pública en América Latina, Benavides. J. L. y Moreno Cruz, P. (eds.), Universidad Externado de Colombia y Fundation pour le droit continental, Bogotá, 20I6, 23-24.

29 Somma, A., "Comparazione giuridica, fine della storia e spoliticizzazione del diritto", en BRUTті, M. у Somma, A. (eds.), Diritto: storia e comparazione. Nuovi propositi per un binomio antico, Max Planck Institut für Europäische Rechtsgeschichte, Frankfurt a.M., en curso de publicación. 
Una perspectiva de análisis que ha inspirado y gobernado, desde el año 2004, la elaboración de los ya mencionados informes anuales Doing Business, y a cuyo análisis específico Somma dedica otras páginas de su libro (pp. I40-I44). Una forma de análisis que, fundamentalmente, patrocina una serie de reformas jurídicas dirigidas a fomentar, con una perspectiva neoliberal, la reducción de los costos de la regulación jurídica soportados por los empresarios para "identificar de este modo modelos virtuosos cuya circulación resulta deseable”. Más allá de las modificaciones en la elaboración de los informes a lo largo de los años -no solo de las variables de análisis empleadas para medir la regulación de cada país, sino también del número de países objeto de análisis y de las metodologías empleadas-, se trata de un proyecto ${ }^{3 \circ}$ dirigido a consolidar una jerarquía que patrocina (y, en mayor o menor medida, impone) reformas y, entonces, circulación de modelos, bajo el entendido de que el modelo del common law, también a la luz de las discutibles conclusiones aportadas por la ya mencionada teoría del origen legal, sería un derecho superior en cuanto más eficiente para garantizar el desarrollo económico y, por tanto, el desarrollo en general ${ }^{3}$.

Por cierto, precisa Somma, se trata de una forma (más o menos impositiva) para desencadenar mutaciones jurídicas que también puede ser rastreada en el escenario jurídico europeo, particularmente en la forma como "se está afrontando la actual crisis de la deuda soberana, cuya reestructuración pasa por la participación del Fondo Monetario Internacional y del mecanismo europeo de estabilidad". Este argumento, que el autor analiza con mucho más detalle en otro de sus trabajos ${ }^{32}$, es presentado con claridad en algunas páginas de su introducción al derecho comparado (pp. I44-I46). Se trata de un fenómeno que, en efecto, muestra una continuidad de las políticas que gobiernan la banca multilateral y que responden, igualmente, a la consolidación, en Europa, del pasaje del capitalismo renano al capitalismo neoamericano y, entonces, a un énfasis en las políticas de matriz neoliberal. En específico, la imposición de reformas jurídicas locales (relativas a la restricción del gasto social, la liberalización del mercado del trabajo y un incremento de los ingresos mediante políticas de privatizaciones y liberalizaciones) como condición necesaria que impone el Fondo Monetario Internacional y, actualmente, también, el Mecanismo de Estabilidad Europea, para acceder a créditos que sirven para subvertir situaciones de endeudamiento en los países europeos que no logran estar dentro de los parámetros-límites establecidos en el pacto de estabilidad.

30 Que, de todas formas, ha sido destinatario de críticas externas e internas (pp. I43-I44).

3 I Ver también Moreno Cruz y Benavides, "La contratación pública en América Latina y la comparación jurídica", cit., 26-30.

32 Somma, A., "Il diritto privato europeo e il suo quadro costituzionale di riferimento nel prisma dell'economia del debito", Contratto e impresa, 20 I6, I 24 - I 58. 


\section{V. ¿Cómo comparar?}

Tal vez uno de los aspectos más complejos y menos consolidados en la ciencia del derecho comparado es el aspecto metodológico. No han sido pocas las propuestas metodológicas y los debates que las circundan. El carácter, por decirlo así, "parasitario" del derecho comparado, aunque no por ello carente de una cierta autonomía epistemológica, ciertamente no ayuda: la comparación jurídica, más ahora que antes, tiende a construir sus propias metodologías sirviéndose, y reformulando, los aportes propios de la epistemología de otras ciencias sociales. Así, la sociología y la historia, la filosofía, la lingüística, la teoría literaria, el poscolonialismo, el feminismo y hasta la geografía crítica, entre otros, han jugado un papel relevante en la configuración de las diferentes propuestas metodológicas de la comparación jurídica: del cómo de la comparación jurídica.

Pues bien, en la última parte de su libro, Somma se ocupa de este argumento analizando, desde una perspectiva crítica, cuatro grupos de propuestas metodológicas: el estructuralismo, el funcionalismo, el análisis económico-jurídicocomparado, las escuelas posmodernas. Se trata de cuatro grupos de metodologías que, en realidad, son las más clásicas, las más relacionadas con el escenario jurídico italiano y, por cierto, en su conjunto, la matriz de muchas otras que se han ido configurando a raíz de las inevitables revisiones críticas.

En primer término, el método estructuralista (difusionista: ver supra Iv), que en Italia puede ser conectado con la teoría de la disociación entre los formantes o entre fuentes del derecho, elaborada por Rodolfo Sacco: una metodología antiformalista que Somma vincula a una evidente resistencia al positivismo jurídico o, mejor -aunque el autor no es claro en este punto-, al positivismo ideológico; no cierto (digo yo) aquel positivismo metodológico que, de hecho, comulga con (y precede) este enfoque y, en cierta medida, lo supera y lo desmiente, al menos en cuanto respecta a algunas de las críticas contra el positivismo jurídico tout court gestadas al interior de la ciencia jurídica comparada ${ }^{33}$.

Somma -adscribiendo el estructuralismo al primer grupo de enfoques comparados, dentro de la distinción arriba mencionada entre comparación que une y comparación que divide-, aunque valoriza la utilidad de esta metodología (de hecho, la ejemplifica mediante el análisis de la noción de contrato en el derecho

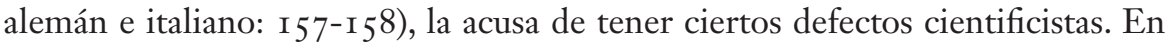
efecto, le reprocha el pretender la identificación de algunas estructuras en los diferentes sistemas jurídicos que, en cierta medida, serían impermeables a los factores culturales (al contexto) del sistema objeto de análisis: "al identificar las estructuras de los ordenamientos y confirmar así su permeabilidad respecto al

33 Sobre el positivismo metodológico ver, recientemente, Chiassoni P., El discreto placer del positivismo jurídico, Moreno Cruz, P. (ed.), trad. Moreno Cruz, M. A., Universidad Externado de Colombia, Bogotá, 2016, passim. 
contexto, el estudioso puede suministrar indicaciones precisas sobre el estado de los objetos en relación con una determinada propiedad" (p. I 56). De hecho, Somma refuerza su crítica al reconducir el estructuralismo a una perspectiva en cierta medida positivista (de nuevo, digo yo, no ciertamente aquella epistemológica), en cuanto suponer la posibilidad de identificar plenamente el contenido de cada formante 34 implica "multiplicar (más que superar) los defectos del positivismo. Los estructuralistas no creen en la unicidad de la regla jurídica, pero creen que pueden identificar la pluralidad de las reglas anunciada por la disociación entre formantes, cuya coherencia interna sostienen" (p. I 56 ).

En cuanto al método funcional, Somma precisa que se trata de una metodología igualmente construida como resistencia al positivismo jurídico (ideológico) en Alemania y, en cierta medida, en Estados Unidos. Recordando la conexión entre el enfoque factualista de Ernst Rabel 35 y el método funcionalista adscrito, en su primera formulación compacta, a los comparatistas alemanes Konrad Zweigert y Hein Kötz, Somma precisa que se trata de una metodología que asume que "aunque en todas las sociedades se recurre al derecho para resolver problemas análogos, las soluciones adoptadas a nivel técnico-jurídico son a menudo divergentes".

Sin embargo, Zwiegert y Kötz consideran que, de todas formas, los diferentes ordenamientos jurídicos, en realidad, tienden a solucionar el mismo tipo de problemas de la misma forma, a pesar de las divergencias técnico-jurídicas: esto permite asumir, según los autores, una presunción de similitud válida para la mayoría de los ordenamientos, o, al menos, en palabras de ambos comparatistas, en los "ámbitos no comprometidos por juicios de valor e imperativos morales", o, que es lo mismo, respecto de unas supuestas áreas del derecho apolíticas. En otros términos, excluyendo el derecho de familia, personas y sucesiones, el derecho no estaría comprometido por valores: en concreto, el derecho patrimonial (el mercado) sería apolítico.

Esta presunción de similitud ha sido destinataria de varias críticas, y de varias reformulaciones. La crítica de Somma, que se adiciona a varias otras -y que obviamente está precedida por una convicción más general, que se comparte plenamente, sobre la imposibilidad de imaginar un derecho apolítico-, puede ser sintetizada en dos afirmaciones destructivas: i) el mercado es sin duda político y,

Esto, para el estructuralismo, en atención a la operatividad real de las fuentes del derecho, que puede contrastar con cuanto los juristas locales digan: el contraste entre regla operacional y declamación de los juristas. Regla operacional condicionada, también, por los criptotipos que, por cierto, solo un punto de vista externo al del jurista local permite identificar. Como precisa Somma, refiriendo a la metodología estructuralista: "para combatir los vicios que denuncian los comparatistas hay que superar precisamente el punto de vista del operador del derecho estudiado, que permitiría identificar los formantes verbalizados o, de algún modo, explicitados, pero no los 'modelos implícitos' o 'criptotipos': los preceptos que presiden la distribución imperativa de valores y bienes, sin que sus destinatarios tengan plena conciencia de ellos” (p. I60).

Rabel, E., The Conflict of Laws, vol. I, University of Michigan Press, Ann Arbor (Mich.), I 945. 
entonces, está condicionado por valores (piénsese, solo, en la incidencia que tuvieron, en la tradición jurídica occidental, las elecciones entre capitalismo renano y capitalismo neoamericano); y, ii) no obstante la carga política del derecho, incluyendo el derecho de sucesiones, familia y personas, es posible identificar, desde una perspectiva comparada, problemas y soluciones equivalentes (en un alto grado de similitud) entre diferentes ordenamientos.

Se trata de una presunción que, además, se vuelve el preámbulo justificativo de otra aserción formulada por los autores alemanes que, igualmente, ha sido destinataria de críticas (o, al menos, relativizaciones) internas y externas, según la cual solo es comparable aquel derecho que soluciona los problemas de forma similar: la función concreta para solucionar problemas específicos es lo que permite la comparación jurídica en cuanto allí es donde se encuentran las similitudes entre las diferentes realidades jurídicas.

Somma considera que se trata de un enfoque metodológico adscribible, así como el estructuralismo, a la comparación que une, que unifica, bajo la presunción de que la comparación jurídica cumple su función precisamente en el terreno de un supuesto derecho apolítico y, entonces, con vocación universal.

Una perspectiva de análisis que, por cierto, pareciera sugerir la posibilidad de identificar un mejor derecho. En efecto, el cotejo entre soluciones (funciones) puede servir para legitimar propuestas que, en atención a ciertos criterios -como, p. ej., la eficiencia-, abren paso a análisis que, prescindiendo de las particularidades específicas de cada territorio, confían a la investigación cuantitativa las reformas dirigidas a afrontar los problemas (presuntamente iguales) con base en soluciones homogéneas. Este es el caso de algunas de las vertientes metodológicas -específicamente el llamado análisis económico-jurídico-comparado (pp. r64-I69)- que, siguiendo algunas tendencias propias del análisis económico del derecho, encuentran su expresión más notoria en las ya mencionadas propuestas de la Nueva Economía Comparada.

En términos generales, en el marco de las propuestas metodológicas de la ciencia comparada, es evidente la tendencia hacia la comparación que une (también dentro de los matices que se generan entre los límites de las metodologías estructuralistas y funcionalistas): sea porque efectivamente es posible identificar amplias similitudes entre los sistemas, sea porque existe una tendencia (de orden prescriptivo) a generar modelos fungibles a nivel global. Esto se explica, como precisa Somma, a raíz de la actual re-formulación y, entonces, la mutación de los "procedimientos" 36 y de las "formas" 37 que gobiernan el nuevo escenario globalizado, caracterizado, entre otros fenómenos, por la "crisis de la soberanía

36 "Superación del government a favor de la governance" (p. I 70), donde destinatarios y productores de los preceptos coinciden.

37 Fuentes del derecho en la forma de red y no de pirámide, así como un amplio recurso al soft law. 
estatal" y por la "irrupción en la escena de nuevos actores, dispuestos a erosionar los espacios abandonados por los viejos actores" (p. I69).

Esta tendencia hacia la comparación que une, en el contexto de un fenómeno "capaz de provocar una notable homologación a nivel planetario de las esferas en las que se verifican las típicas rupturas de fronteras, las esferas políticas, económicas y culturales" (p. I 7 I), condujo a una respuesta al interior de la ciencia comparada con las ya mencionadas metodologías posmodernas de la comparación jurídica: una comparación que divide, una forma de comparación que debe enfatizar las diferencias entre los objetos de comparación, ojalá evidenciando "críticamente las maneras en las que esas diferencias pueden ser ocultadas en clave unificadora o, por el contrario, promovidas en términos también abiertamente preceptivos" (p. I72).

Por supuesto, como Somma precisa ya en otras partes del libro, la comparación que divide, al igual que la que une, corre el riesgo de conducir a visiones parcializadas (y entonces engañosas) en las conclusiones del ejercicio comparado. No obstante, las perspectivas post-modernas (de cuyo adjetivo, por cierto, se podría discutir en cuanto varias de sus perspectivas pueden ser reconducidas a algunas lecturas de la modernidad) tienen ciertamente una ventaja a los ojos del autor, no solo por el hecho de presentarse como una tendencia anti hegemónica, sino por el hecho de que ponen "de manifiesto la circunstancia de que el derecho es manipulable y manipulado por quienquiera que se asuma el rol de fuente substancial de preceptos: se accede a este punto de vista externo sobre el derecho que se muestra indispensable para evidenciar, entre otras cosas, la complejidad del derecho global" (pp. I73-I 74).

\section{SOMmaS Y RESTAS}

La empatía de Somma con las perspectivas metodológicas que valorizan el pluralismo jurídico y se oponen a las perspectivas unificadoras, $\mathrm{y}$, entonces, con pretensiones universalistas, no le impide formular algunas recomendaciones de orden epistemológico que, por cierto, seguramente orientan su libro y que, en concreto, él ejemplifica mediante el análisis de dos argumentos: i) el uso del derecho romano (pp. I78-I85) y ii) la estructura del consenso contractual (pp. I 85-189).

Su propuesta metodológica, que Somma denomina disociación entre técnicas $y$ valores, toma en serio la "ausencia de una correspondencia entre derecho y sociedad" o, en términos más precisos, la "indicación de que debe procederse a una disociación entre las técnicas jurídicas y los valores a cuya implementación van dirigidas esas técnicas" (p. I 76). En otros términos, el análisis comparado, es decir, ese análisis (digo yo, descriptivo) dirigido a la identificación de similitudes y diferencias entre realidades jurídicas, solo es posible si se asume que existe una relación inestable "entre el poder (y el derecho es solo una de ellas) y el valor 
que el poder pretende promover (también mediante el control sobre el discurso jurídico) para afirmarse primero y perpetuarse después” (p. I 76). De este modo, el aspecto central parece ser aquel del análisis y el "control sobre los significados atribuidos al lenguaje jurídico" ${ }^{3}$.

En suma, podría decirse, (no solo) un "análisis meta-jurisprudencial" dirigido a una "caza de las ideologías"39: (entonces) un análisis -(digo yo) en parte tarelliano- que sirva, sobre todo, para capturar la complejidad que se desata en las transiciones (reiteradas, en algunos casos, excepcionales, en otros) de significados donde "emergen las continuidades y las rupturas en la sucesión de los poderes, en las que el derecho exhibe su esencia de técnica puesta al servicio de los valores en torno a los cuales se consuma el conflicto social” (p. I77). Un análisis que, como ya ha sido precisado, se debe detener, no solo en los enunciados producidos por las fuentes del derecho formales, sino en cualquier enunciado con efectos normativos producido por cualquier centro de interés, también por aquellos hostiles. Un análisis que considera relevante (no tanto el análisis de la validez de las respectivas normas, sino) su (in)eficacia. Un análisis que, en fin, debe reconocer en su ejercicio comparado el evidente pluralismo jurídico, desechando las pretensiones etnocétricas y las clasificaciones funcionales a intereses diferentes de aquel de (para ser claro) describir el conflicto entre los diferentes centros de interés y mostrar cómo los mismos condicionan la realidad social.

Tal vez, precisamente a raíz de esta perspectiva metodológica, Somma, en su Introducción al derecho comparado, no parece detenerse en los tradicionales argumentos, tópicos y narraciones que construyen un curso de derecho comparado. En efecto, creo que es posible identificar, además de lo dicho en relación con la disociación entre técnicas y valores, seis tópicos que gobiernan el libro: i) una crítica al positivismo ideológico; ii) una crítica a las perspectivas evolucionistas; iii) una crítica a la construcción de las periferias globales a partir de una crítica a la (re) construcción jerarquizada y etnocéntrica de la tradición jurídica occidental y sus efectos geopolíticos; iv) una crítica a la adscripción de una función unificadora al derecho comparado que niega la relevancia de las particularidades culturales locales; v) una crítica a las perspectivas comparadas que identifican derechos supuestamente apolíticos o, de todas formas, ajenos al condicionamiento de los diferentes centros de interés en el contexto de las mutaciones jurídicas; vi) una crítica a la hegemonía de la Nueva Economía Comparada hija de la hegemonía del capitalismo neoamericano y, entonces, de una desequilibrada relación entre democracia y capitalismo.

$3^{8}$ Recuerdo que Somma parte del supuesto según el cual la interpretación es una práctica política dirigida a concretar una específica "distribución imperativa de valores y bienes, es decir, una modalidad para concretar compromisos en torno a varias opciones sobre el modo de coordinar intereses contrastantes" (p. 32).

39 Sobre el argumento ver Chiassoni, El discreto placer del positivismo jurídico, cit., espec. cap. v, "Tarello y la desmitificación del pensamiento jurídico". 
La elección me parece clara: restar importancia o, mejor, dar por conocido el dato comparado tradicional y su tradicional reconstrucción, para sumar a su trabajo la posibilidad de narrar el derecho, los derechos, desde una perspectiva diferente: en síntesis, desde una perspectiva crítica, a partir de una comparación de las comparaciones jurídicas, con el objetivo de develar las ideologías específicas que alimentan a la ciencia comparada. 